\title{
Las caras de Jano. Teorías actuales sobre la democracia en América Latina
}

\author{
Lucio Oliver Costilla
}

FCPYS-UNAM

A

continuación ofrecemos al lector una revisión de obras recientes que presentan el estado actual de la discusión sobre la democracia política en América Latina.

Es un hecho de sobra conocido que en la década anterior hubo una generalizada restauración y profundización de esta forma del Estado capitalista en el subcontinente. ${ }^{1}$ Resulta funda-

1 "Los ochenta fueron años de restauración y profundización de la democracia política en América Latina. Por un lado, la gran mayoría de los regímenes autoritarios fueron desapareciendo y dando lugar a noveles democracias políticas. Por otro, la creciente participación política ciudadana y la alternancia de partidos en el gobierno caracterizaron la evolución de los mental tratar de entender las carac. terísticas que ha adquirido y su significado institucional y político, así como dilucidar su influencia en el desarrollo total de las sociedades de la región.

Hemos elegido tres obras relevantes sobre el tema a partir de que, 1)

pocos regímenes constitucionales que durante los sesenta y setenta subsistieron en la región. Como consecuencia de estas transformaciones, América Latina inicia el último decenio del siglo con la mayor cantidad de democracias políticas que haya tenido simultáneamente en toda su historia", Emmerich, "América", 1991. Hacemos la aclaración de que la discusión específica de la situación de la democracia en Cuba no es parte de la temática discutida por los autores de los trabajos consultados. 
son el resultado de un esfuerzo colectivo, y por ende la síntesis de un proceso intelectual de discusión entre numerosos académicos y políticos; 2) expresan vertientes teóricoconceptuales con una personalidad definida y con determinada incidencia en las polémicas académicas y políticas de hoy; 3) constituyen apreciaciones que van más allá de las definiciones abstractas y politicistas sobre la democracia, para tratar de abordar el problema en términos de los procesos globales del desarrollo latinoamericano, y 4) están orientadas a pensar el problema también en los años venideros; son, en ese sentido, lecturas abiertas a las tendencias de finales de siglo.

Los textos seleccionados coronan un esfuerzo de investigación y de discusión de sus autores que duró varios años, y son la síntesis de múltiples estudios particulares, realizados por conductos diversos y con metodologías distintas y hasta opuestas, lo cual precisamente hace atractiva su inclusión en este análisis.

El primer libro, de George Iandau, Julio Feo y Akio Honoso, se denomina América Latina en la encrucijada; el desafio de los países de la Trilateral, ${ }^{2}$ y fue discutido en su elaboración por más de treinta académicos, estadistas y dirigentes empresariales; representa el punto de vista dominante de los gobiernos de Estados Unidos, Canadá, la Comunidad Económica Europea y Japón.

El segundo texto, de Fernando Calderón y Mario $R$. dos Santos se titula Hacia un nuevo orden estatal en América Latina, ${ }^{3}$ y representa las con-

2 Landau, América, 1990.

3 Calderón y Dos Santos, "Nuevo", 1990. clusiones del proyecto regional PNUDUNESCO-CLACSO, "crisis y requerimientos de nuevos paradigmas en la relación Estado/sociedad y economía". Además de los autores, y de los numerosos participantes en los proyectos específicos, ocho académicos participaron colateralmente en la tarea de síntesis. El enfoque expresa la búsqueda renovadora en pos de nuevos paradigmas teórico-políticos para el estudio de los problemas de la región.

La tercera obra, de Pablo González Casanova, "El estado y la política", publicado en América Latina boy," recogió para su elaboración la discusión de 22 autores, publicada en otro texto bajo su coordinación denominado $E l$ Estado en América Latina. Teoria y práctica. ${ }^{5} \mathrm{El}$ autor expresa la perspectiva de la sociología radical de América Latina.

\section{ENTRE LA CIVILIZACIÓN Y LA BARBARIE. LA CONCEPCIÓN POLÍTICA DE LA COMISIÓN TRILATERAL}

En el balance de la situación actual de América Latina, la comisión considera altamente positivo que la mayor parte de los países de la región hayan alcanzado el objetivo universal de la democracia. ${ }^{6}$ Se trata de un dificil

4 González Casanova, América, 1990.

5 González Casanova, Estado, 1990.

6 "De hecho, con la excepción de Cuba [hoy quiza Haití y Perú, L.O.C.], todos los países de la región actualmente tienen democracias en funcionamiento o se encaminan aparentemente hacia ese objetivo universal", Landau, América, 1990 , p. 49. 


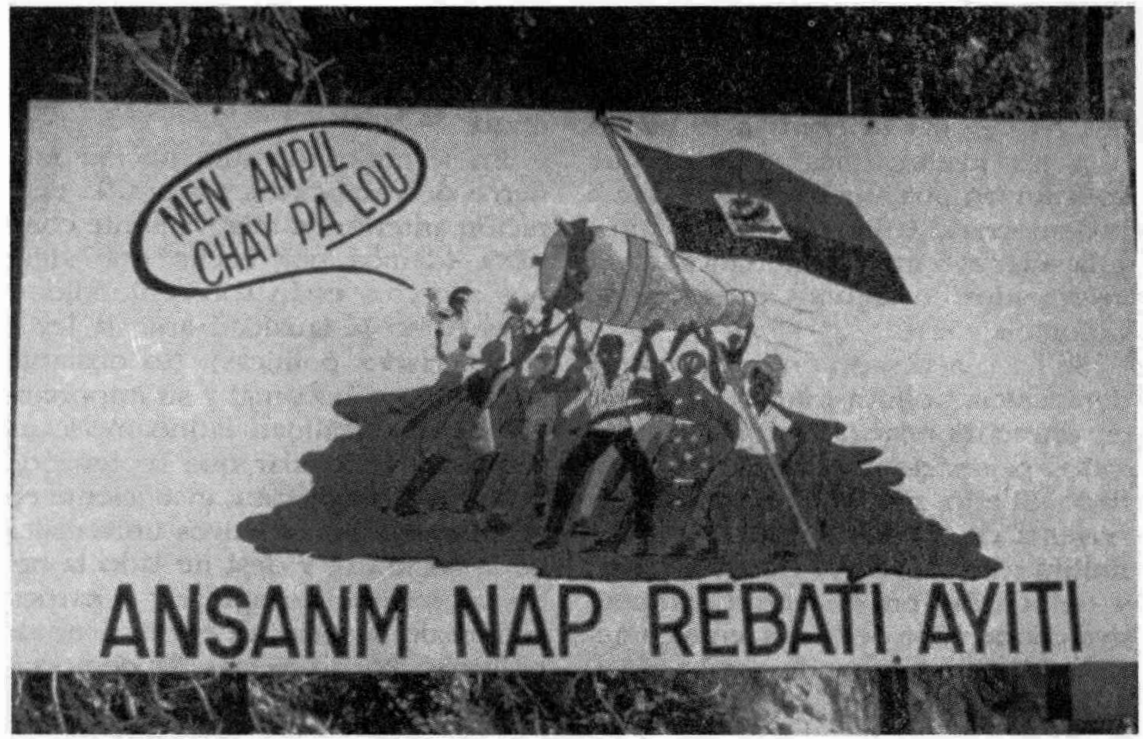

cambio de valores que ha terminado por dejar atrás el estatismo y el aislamiento nacionalista. ${ }^{7}$ Las cosas, sin embargo, no marchan del todo bien y hay indicios de inestabilidad. ${ }^{8}$ Las dificultades, empero, no provienen del funcionamiento mismo de la democracia política, sino de los males sociales (una pobreza opresiva, una grave falta de infraestructura social, la sobreexplotación del medio ambiente, así como la corrupción y la violen-

7 "Los anticuados y disfuncionales estatismo y xenofobia económica de los sesenta y setenta, que cada vez se consideran arruinados y desacreditados, retroceden claramente y el atractivo del marxismo revolucionario decae", ibid.

8 "Muchas naciones se han atascado en el camino deseado hacia la modernización política, el crecimiento económico y las mayores oportunidades sociales", ibid. cia), producto de los lentos resultados de las reformas económicas en marcha, y de las consecuencias disruptivas de la crisis económica de la "década perdida". 9

Hay entonces "repercusiones políticas" y no disfunción institucional. Una "situación social insostenible" amenaza a la democracia política latinoamericana. Según la comisión, las dificultades económicas que alimentan esa situación social no se han logrado superar aún debido a la "falta de vo-

9 "Ia década anterior se caracterizo por la carga debilitadora de la deuda, la fuga de capitales, la reducción de la inversión, el estancamiento económico, y el perverso espectáculo que ofrecían estos países al exportar sistemáticamente más capital del que recibían", ibid., p. 51 . 
luntad, inteligencia y seguridad de los latinoamericanos". ${ }^{10}$

Para la Trilateral existen asimismo dos fenómenos externos a la región - a las instituciones políticas que constituyen una amenaza intrínseca a la democracia latinoamericana: Cuba, y la alianza entre narcotraficantes e insurgentes en algunos países como Colombia y Perú.

Se hace necesario entonces que la democracia política interior se apoye en estrechas relaciones con los civilizados países de capitalismo desarrollado. El reto, por tanto, para los años noventa es: "la búsqueda de una de. finitiva integración de América Latina y del Caribe en el marco competitivo/cooperativo de la creciente comunidad de democracias desarrolladas". ${ }^{11}$

La cuestión para la comisión es mantener las democracias en funcionamiento y lograr que los países que se encaminan a alcanzarlas lo realicen a la brevedad. La democracia política es un valor dado, y un objetivo más o menos unívoco, pero tiene sus complejidades como veremos a continuación.

La comisión sostiene que la principal cuestión política para América Latina es conseguir y mantener formas viables de gobierno democrático. Para ello nos dan a conocer su concepción de la democracia ideal, misma que se basa en cuatro pilares: "elecciones váli-

10 "Una comunidad internacional próspera parece ofrecer oportunidades económicas a aquellos que tengan la voluntad e inteligencia para aprovecharlas. Pero las naciones de América Latina y del Caribe se encuentran inmersos en grandes dificultades y no parecen estar muy seguras de cómo insertarse en el contexto internacional", ibid., p. 53.

11 lbid., p. 53. das periódicas, respeto a los derechos y a las libertades humanas, un grado sustancial de justicia social y gobierno eficaz". ${ }^{12}$

En términos de una noción moderna de democracia política, la definición anterior es relativamente completa (damos por hecho que algunos aspectos están sobreentendidos, tales como la igualdad ante la ley y las libertades políticas). No obstante su riqueza conceptual y su importancia para la realidad latinoamericana actual, cabe señalar que se trata de una visión pragmática, insuficiente en términos de los objetivos universales de la sociedad, y deja de lado la necesaria soberanía popular y la participación de la sociedad en los asuntos políticos. Por lo demás, la democracia política requiere de un Estado afirmado en el ámbito nacional, capaz de integrar a las distintas clases y grupos sociales y de procesar una hegemonía histórica de dirección política. Y eso no parece ser un problema para la Trilateral. La democracia debe, según su concepto, responder más a la modernización de la cultura política y a la instalación de valores que a la construcción histórica y política de las instituciones. ${ }^{13}$

12 "Democracia en este contexto significa no sólo la celebración de elecciones válidas periódicamente, sino también esforzarse de buena fe para que se respeten los derechos y las libertades humanas básicas y la consecución de un grado sustancial de justicia social. También significa un gobierno que sea capaz de funcionar con eficacia, resolver pacíficamente las diferencias internas de opinión y activar políticas que sean realmente beneficiosas para las sociedades locales", ibid., p. 86.

13 "La cultura política de la región debe ser modernizada a fin de instalar los valores de la 
La noción de democracia política de la Trilateral es un ideal-objetivo dominante en los países de capitalismo avanzado (las "democracias desarrolladas"), no obstante, el planteamiento no nos dice nada sobre las condiciones de su existencia y advenimiento en sociedades como las nuestras. Pareciera como si la existencia de la democracia política estuviera al margen del proceso de desarrollo real de las sociedades, la dependencia y el atraso económico, la desarticulación nacional, la falta de integración estatal, etcétera. ${ }^{14}$

Otro punto fundamental, dejado de lado por la noción de democracia ideal de la Trilateral, es el relativo a la participación popular autónoma en los procesos de decisión esenciales. Esta ausencia muestra la pobreza de la idea republicana de la comisión. Lo cual no es extraño si sabemos que

tolerancia, el realismo y la eficiencia, que son necesarios para que una democracia sobreviva en cualquier lugar [...] Todos los sectores de la sociedad -los empresarios, los trabajadores, la prensa, los intelecruales e incluso las fuerzas armadas- deben encontrar su sitio dentro de marcos democráticos viables y el sistema debe funcionar proporcionando soluciones justas para los conflictos y una dirección política adecuada al tiempo que se permite y se fomenta que las iniciativas $e$ instituciones privadas de. sempeñen su papel fundamental. A su vez, esto requiere una dirección valerosa y capaz de los políticos y los partidos políticos", ibid., p. 88 .

14 La existencia pasajera de la democracia en Hait, por ejemplo, para esa concepción, quizá debe explicarse debido a una iluminación civitizatoria de unos meses que desapareció ante la bruma de la real ignorancia de los nativos, y seguramente no tuvo nada que ver con la resistencia de décadas al duvalierismo y con la capacidad de articulación hegemónica de Aristide. en las "democracias desarrolladas" de los países capitalistas avanzados dicha participación popular autónoma es bastante precaria.

La comisión demuestra una real preocupación por generar las condiciones socioeconómicas que podrán sostener la democracia política, en especial alude a la incertidumbre que aún prevalece respecto de lograr la modernización económica, ${ }^{15}$ sin ninguna referencia al problema de los límites y condicionantes que produce un mercado mundial dominado por las empresas trasnacionales. Para la Trilateral, la democracia funciona de acuerdo al grado de instalación de valores en la sociedad; su preocupación por la economía es "exterior", se refiere al sostenimiento económico de las instituciones. La propia economía es una cuestión de valores para esta vertiente teórica: el problema con América Latina es saber si nuestros países lograrán cambiar su esquema conceptual estatista y proteccionista endógeno de desarrollo, por otro abierto, basado en la competitividad y en la cooperación dentro del mercado mundial.

15 "El problema económico fundamental al que se enfrentan las naciones de América latina y del Caribe es si serán capaces de forjar sistemas modernos de producción que puedan satisfacer las necesidades materiales de sus sociedades y de sostener las legítimas aspiraciones sociales y políticas de sus miembros. Tales sistemas económicos deberán ser competitivos en una economia mundial liberalizada y capaces de producir unas pautas fuertes y sostenidas de crecimiento $y$, simultáneamente, de distribuir los frutos de esta expansión de un modo razonablemente equitativo", Landau, Amb́rica, 1990, p. 89. 
A pesar de la inclinación inicial por los valores de la democracia, parece que los propios intelectuales, empresarios y políticos de la comisión no están del todo convencidos sobre la madurez cultural de nuestros pueblos. En el texto dejan claro que si los pueblos de la región no controlan a sus elementos violentos e incontrolados, que responden a la amargura creciente de la situación social, el problema se transforma en un problema de seguridad para el cual hay que disponer y utilizar la fuerza:

Una mera disposición a la negociación sin apoyarse por lo menos en la posibilidad de emplear la fuerza no es, generalmente, eficaz para enfrentarse a los elementos violentos e incontrolados, que son la esencią de la mayoría de las amenazas político-militares a las sociedades democráticas civilizadas y, $\mathbf{s i}$ fracasan las negociaciones, la dirección de medidas de fuerza (o la dirección del país para su aplicación) no debería recaer necesariamente en manos exclusivamente militares. ${ }^{16}$

INNOVACIÓN INSTITUCIONAL Y CRÍTICA DE IA MODERNIZACIÓN SOCIALMENTE EXCLUYENTE DEL ESTADO. LA CONCEPCIÓN CORRECTORA DEL CONSEJO LATINOAMERICANO DE CieNCIAS SOCIALES (CIACSO)

Para Fernando Calderón y Mario R. dos Santos, directivos de clacso, la situación de la democracia en la región tiene como referencia ineludible los necesarios ajustes estructurales y la

16 Ibid, p. 109. "inevitable" reinserción de los países latinoamericanos en la economía mundial (tesis 1 y tesis 2). Para estos autores, lo mismo que para la Trilateral, con la crisis de la década de los ochenta y con las nuevas políticas neoliberales y de fomento a las exportaciones se da fin al "ciclo de un patrón estatal organizador del desarrollo", a la postre ineficiente (tesis 3) ${ }^{17} \mathrm{Lo} \mathrm{pe}-$ culiar de la visión de clacso consiste en que para ellos dicho fenómeno lleva implícito un desplazamiento ya vigente del núcleo de decisiones del Estado hacia el conjunto del sistema político.

Los planteamientos anteriores son verdades a medias. Con relación al primer aspecto los autores aseveran que el Estado latinoamericano posterior a la crisis de los años treinta se convirtió en el centro articulador de las relaciones entre la sociedad y la economía. ${ }^{18}$ Además, el Estado, y en particular su poder ejecutivo, se convirtieron en el eje de las decisiones, desplazando al sistema político general. Este planteamiento da una explicación histórica adecuada del proceso de concentración del poder político en granparte de las sociedades de la región. Para esta explicación, la prolongada antidemocracia en muchos de nuestros países desde 1930 no es resultado de una ausencia de valores y de cultura política, sino de un patrón de desarrollo estatista. Esta perspectiva resulta más adecuada que la de la Trilateral, sin embargo, los autores se en-

17 Calderón, y Dos Santos, "Nuevo", 1990, p. 52.

18 " $[\ldots]$ articulando el desarrollo económico y las relaciones socio-políticas nacionales", ibid. 
golosinan con el estatismo de tal manera que lo transforman en el eje de toda la historia y de las mismas relaciones sociales: el Estado se convierte en un sistema de acción histórica. ${ }^{19}$ Este planteamiento no advierte que el Estado es una relación social de poder institucionalizada, y que difícilmente puede por sí mismo ser el núcleo de la vida social o dar lugar a algo así como un "modo de producción estatal". La sociedad está conformada por clases y grupos sociales cuya relación global (de producción y de interacción sociopolítica y cultural) es la que determina el papel predominante o no del Estado en las formaciones sociales.

Otra idea apresurada de estos autores, que no podría corroborarse, es la de que en América Latina se está produciendo ya un desplazamiento de la toma de decisiones desde el Estado al sistema político, y que esa es una característica básica del proceso de democratización en la región. ${ }^{20}$ En realidad más bien ese desplazamiento no se ha producido a pesar de la democra-

19 "Concurrentemente, el núcleo de actores e intereses sociopolíticos predominantes se constituía en el Estado mismo, y desde allí se organizaban las relaciones con la sociedad y con el sistema internacional. Se puede afirmar que existía un sistema estatal de acción histórica", ibid.

20 "En este contexto, la emergencia de un proceso de democratización en toda la región, con un relativo fortalecimiento de instituciones democráticas y de actores sociales y políticos, a partir de una gama de situaciones y problemas, implica que las decisiones fundamentales se tomen en sistemas políticos, a partir de una gama de situaciones y problemas, implica que las decisiones fundamentales se tomen en sistemas políticos con un juego más amplio para los diversos poderes sociales", ibid., p. 53. tización de los sistemas políticos y de la existencia de un Estado de derecho. Es precisamente la burocracia política ejecutiva como eje de un núcleo de elite empresarial y militar la que sigue teniendo en sus manos las principales decisiones de nuestros países. Ejemplos como'el autogolpe de Estado en Perú, o el desprecio del gobierno de Carlos Andrés Pérez a las demandas populares de cambios radicales en la política económica de Venezuela, demuestran claramente dónde está el verdadero poder de decisión.

Precisamente por lo anterior, los autores no dan una explicación adecuada de un fenómeno contradictorio de integración política y exclusión social que ellos mismos advierten: "la conjugación de un proceso de democratización del régimen político que tiende a ser políticamente incluyente y un proceso de modernización del Estado que tiende a ser socialmente excluyente" (tesis 4). ${ }^{21}$

Es debido a que son sólo unas clases y grupos (la burguesía transnacional y las elites políticas neoliberales) los que determinan las decisiones esenciales, que la modernización del Estado tiene el carácter antipopular y desnacionalizado que presenta, no obstante que otras clases y grupos sociales (la burguesía media y pequeña, las capas medias, la pequeña burguesía, los campesinos, los obreros, los jóvenes, etcétera) participen en buena medida en el nuevo régimen político democratizado, sin tener acceso a las decisiones de la burocra. cia ejecutiva central. Es por esa razón

21 Ibid. 
que los lineamientos que ha seguido la modernización del Estado tienen un marcado signo privado y socialmente excluyente. ${ }^{22}$ Al final, los propios autores dudan de su tesis acerca del desplazamiento de las decisiones y de la democratización sustancial:

Los procesos de democratización parecen derivar hacia la formación de mercados políticos con predominio de particularismos y en los procesos de modernización del Estado no se incluyen tendencialmente mecanismos de integración. 23

Lo que sí parece acertado del planteamiento de CLACSO es que las grandes mayorías han revalorado al régimen democrático y a los actores políticos y sociales, y ese es un logro significativo de la democratización de la región en los años ochenta. ${ }^{24}$

Los directores de clacso nos plantean una apreciación interesante: "si la democratización se produce sin modernización del Estado, se generará ingobernabilidad" (tesis 5). El problema

22 "Énfasis en el ajuste fiscal, desregulación, privatización, descentralización muchas veces con concentración de decisiones políticas, encarecimiento de servicios públicos, reducción del empleo estatal, desmonte de políticas sociales, racionalización de la gestión estatal", ibid.

23 Ibid.

24 "Tales procesos de democratización valorizan pues los actores políticos y sociales, más allá de las calidades que se logren en cuanto a régimen político democrático, desde democra. cias "de equilibrio" -democracias constitucionales tradicionales - hasta marcos institucionales innovados con mejoramientos importantes en los sistemas de representación política y social", ibid. será la “ingobernabilidad económica y potencialmente política y/o del sistema en su conjunto". 25 Los autores tienen razón en términos de la ingobernabilidad que provocaría el in. sistir en un modelo de acumulación de capital y en un patrón de desarrollo endógeno concentrador que funcionó en el periodo de 1945-1980 y que se agotó desde hace más de una década. Pero lo que haria falta considerar con mayor amplitud es la perspectiva de una política de democratización con modernización popular del Estado, lo cual conllevaría otro tipo de gobernabilidad económica y política.

Por otra parte, los autores advierten que una aplicación estricta de la modernización antipopular y socialmente excluyente del Estado puede llevar directamente a la quiebra de la democracia política por medidas de fuerza, ${ }^{26}$

25 "Existieron en la región procesos de democratización en los cuales se resistió fuerte. mente la aplicación de una política económica de ajuste estructural (intentando mantener la demanda global y el nivel de actividad economica, inclusive agregando objetivos de redistribución del ingreso). Se resistió también la aplicación de políticas de modernización del Estado, en particular las que hacen al ajuste fiscal. Invariablemente esos intentos, al no lograr recuperaciones de la tasa de inversión en los plazos en que aquellas políticas no ortodoxas aún eran viables, desembocaron en situaciones de ingobernabilidad económica y potencialmente política y/o del sistema en su conjunto", $i b i d$.

26 "Aun sin hacer ninguna referencia a dere. chos sociales y/o derechos de los pueblos (constitucionalismo social propio de Estados sociales de derecho que tiende a ampliarse en las reformas actuales a las Cartas Magnas) se advierte el riesgo de transgredir, en función del mantenimiento del orden público, dimensiones estrictamente formales inherentes a una definicion mínima de régimen democrático. Por ejemplo, 
con lo cual le otorgan una explicación sociopolítica al problema que la Trilateral planteó en términos de la necesidad potencial de hacer uso de la fuerza por la quiebra de los nuevos valores culturales.

Otra tesis de los directivos de CLACSO que parece bien sustentada es la de que todos los actores sociopolíticos principales deben asumir el compromiso conjunto de defender sus intereses dentro de la institucionalidad democrática, de otra manera no hay democracia (tesis 6). Aciertan al señalar a los actores estatales como los principales responsables de este compromiso y de su violación. ${ }^{27}$

Calderón y Dos Santos cuestionan la intervención externa en la consolidación democrática de la región, especialmente la nortamericana. Sostienen que dicha intervención hace énfasis en el ejercicio electoral y deja de lado la vigencia de un régimen político que permita la representación de la pluralidad sociocultural existente en nuestras sociedades, así como la ciudadanía social (tesis 8).$^{28}$

Hay dos tesis básicas que ubican acertadamente el problema del man-

suspensión prolongada de garantías individuales, represiones masivas ante saqueos, deterioros en la juridicidad, etc.", ibid., p. 54.

27 "Cuando se trata de actores políticos estatales o actuantes en los sistemas de representación, la combinación aberrante de metodologías contrapuestas de acción política amenaza o compromete directamente la existencia del régimen democrático. Este último de ninguna manera puede definirse únicamente por la existencia de un marco jurídico democrático, ya que la determinación del régimen comprende los comportamientos de sus actores fundamentales", ibid.

${ }^{28}$ Ibid., p. 56. tenimiento y la profundización de la democracia en la región: una se refiere a la exigencia de que los ajustes económicos estén vinculados a políticas de transformación económica basados en la reconversión y plasmados en un proyecto de desarrollo nacional (tesis 9). La otra tesis cuestiona el entregarle al mercado un papel protagónico en la organización de las relaciones sociales, en desmedro del Estado y de los regímenes políticos (tesis 10). Acertadamente se sostiene que "en nuestros países, el mercado, por insuficiente dinamismo, no puede ser un eficaz integrador social." 29

Otra apreciación básica (tesis 12) es que la desestructuración de los actores sociopolíticos (partidos, sindicatos, movimientos sociales) de la actual modernización estatal no contribuye a fortalecer la democracia y sí a mermar la acción colectiva social en beneficio de la elite económica y política.

Los autores, por el contrario, proponen un proceso de profundización de la democracia por la vía de una renovación institucional que evite el retorno de rasgos no democráticos del Estado latinoamericano tradicional, como patrimonialismo, clientelismo y corporativismo:

Un perfeccionamiento institucional de los sistemas de representación política

29 "Resal ta que la apertura hacia la economía mundial no puede afrontarse exitosamente sin una intervención creciente del Estado, a fin de perfeccionar y ampliar los mercados y de que la orientación exportadora del ajuste no se resuelva en una dualización creciente y en una dependencia directa respecto de centros de decisión y de inversión externos", ibid., p. 57. 
y social, orientado a incrementar la incidencia de la representación en los sistemas de toma de decisiones y la responsabilidad de los actores políticos y sociales en las tareas globales" (tesis 14), ${ }^{30}$

También se señala la necesidad de oponerse a las tendencias dominantes de control transnacional de las políticas culturales, de la industria cultural y de los medios masivos de comunicación (tesis 15). ${ }^{31}$

Al final del texto, con relación a las perspectivas de la democratización de América Latina en los próximos años, los autores reiteran su tesis de que estamos ante el fin del ciclo histórico estatal y ante el inicio complejo de otro ciclo diferente. Sostienen la necesidad de oponerse a las pretensiones de llevar a cabo "procesos de democra. tización subordinados a los éxitos de la lógica del mercado o de las áreas y sectores de interés estratégico militar de los países centrales" (Corolario de cierre)". 32

Los autores proponen otro tipo de democratización que va más allá de la "simple recuperación del Estado de derecho" y que se basa en la "innovación integral". Su idea de una democracia política para los noventa está basada en una innovación institucional que comprometa nuevas relaciones sociopolíticas y nuevas instituciones, más allá del simple Estado de derecho, vinculadas a una propuesta de desarrollo integral que resuelva también el problema económico. La cuestión que

30 Ibid., p. 58

31 Ibid., p. 59.

32 Ibid., p. 65. queda sin tocar en lo específico y concreto de las clases y grupos sociales se refiere a quiénes pondrán en funcionamiento este programa democratizador integral, crítico de las tendencias actuales.

\section{LA PERSPECTIVA DE LA SOCIOLOGÍA RADICAL.}

Pablo González Casanova nos presenta una interpretación radical y sustancial de la situación actual del Estado y de la democracia en América Latina. 33

El autor sostiene que la crisis económica ha acentuado un proceso de transnacionalización del Estado y la sociedad en América Latina, e impuesto un cambio radical en la concepción del desarrollo y de las reformas de estructura. Lo mismo sucede con respecto a la democracia, la cual se define hoy por la participación en las decisiones del poder de sólo una parte de la nueva sociedad dual, conformada por sectores integrados y sectores excluidos. En la medida en que ese proceso de transnacionalización significa que se da fin al "proyecto histórico de la independencia política y económica de las naciones y al desarrollo económico y social equilibrado", la propia democracia no está vigente en tanto la participación institucional popular está opacada por el proceso de transnacionalización:

33 Su texto, titulado, "El Estado y la política", está precedido por un estudio de la crisis económica de la región en la década anterior y de la propuesta de una estrategia transformadora alternativa por parte de Vuscovic. Véase Vuscovic, "Economía", 1990. 
[...] el Estado, dominado por los bloques de la burguesía asociada, tiende a organizar la dependencia y la "sociedad dual" como estructura tcansnacional $e$ interregional global, $y$ al efecto emplea toda la lógica de la represión, de la dominación y de la expla tación buscando "optimizar" funciones y programas. ${ }^{34}$

Dos afirmaciones establecen los nuevos límites de la democracia política actual en América Latina, y en los hechos la inexistencia de la democracia política: 1) "La empresa transnacional en América Latina es más poderosa que el Estado nación, al que penetra y con el que se asocia. Si hay sectores o zonas que se desarrollan, lo hacen predominantemente en función de las empresas transnacionales"; ${ }^{35} 2$ ) "La nación como soberanía y como mayoría es cada vez más gravemente afec. tada. Lo soberano no es nacional ni es mayoritario... La mayoría ni es soberana, ni es participante, ni es influyente. No existe ningún indicio de que ocurra lo contrario." 36

Si no hay Estado soberano, no hay democracia política alguna. Lo que existe, a decir de González Casanova, es una política de Estado para eliminar la injerencia del Estado en la solución de los problemas nacionales, y además para desarticular "las media. ciones políticas, sindicales, agrarias y la seguridad social del Estado benefac. tor", sustituyéndolas por otras basadas en el mercado y en la economía informal.

Para González Casanova, a pesar de

34 Ibid., p. 67.

35 Ibid., p. 69.

36 Ibid. la merma en cuanto a soberanía nacional y a democracia política real, el Estado latinoamericano transnacionalizado mantiene la imagen de ser un poder público autónomo y nacional debido a la inercia de una burocracia institucional y por los mitos ideológicos de su propio poder, mismos que esconden el proyecto transnacional, oligárquico y de clase. 37

Si bien la democracia política realmente no está vigente, lo que sí se presenta, según González Casanova, es la apariencia de la democracia, el mundo de las formas constitucionales, jurídicas, democráticas y liberales, mismo que intenta ocultar y contrarrestar la vulnerabilidad del Estado transnacional.

El proceso de transnacionalización iniciado en los sesenta ha colocado al Estado en una situación represiva y de clase que lo hace muy vulnerable. La crisis económica de los setenta y ochenta ha aumentado esa debilidad. Por eso el gobierno de Washington $y$ las clases dominantes de Estados Unidos y América Latina han considerado necesario recrear las mediaciones perdidas y volver al mundo de las formas constitucionales. ${ }^{38}$

37 "El Estado asociado al proyecto transnacional, oligárquico, de clase, no sólo se beneficia de la desarticulación de la nación y las clases subalternas, sino de los mitos de su propio poder y de las ideologías ilusorias. Es más, a su poder coercitivo y al uso necesario de la violencia en los puntos críticos y en los momentos decisivos añade siempre su disciplina burocrática interna, militar y civil, que aparte de coordinar y unificar los mitos, creencias e ilusiones, coordina las acciones de los aparatos de Estado, con lo que, al poder coercitivo, el Estado añade el poder de la disciplina institucional", ibid., p. 74. 38 Ibid. 
Por lo anterior, el autor nos llama a distinguir entre el poder real $y$ las formas, ${ }^{39}$ lo cual demuestra la precariedad del funcionamiento democrático aunque se cumplan ciertos patrones de comportamiento institucional.

En los diferentes sistemas políticos fácilmente aparece el poder que se oculta y subyace tras las formas. El poder como realidad se revela al observar cicrtos patrones de violencia física y lógica que se ejercen contra los sistemas políticos representativos y contra las instituciones y los valores democráticos. ${ }^{40}$

Para González Casanova la ausencia de democracia se expresa como democratización transnacional, "hecha contra la democracia popular revolucionaria. Pero también está hecha contra la socialdemocracia y el populismo" $\$ 1$

39 Hay un planteamiento en González Casa. nova que aclara la relación entre el pođer real del Estado y el sistema político general: "los partidos políticos pueden ser débiles o fuertes en el terreno político, pero en el de la hegemonía del Estado sollo serán tolerados bajo los límites ya establecidos por el Estado y por las clases hegemónicas, a menos que ellos impongan una nueva hegemonía, fenómeno que sale siempre de las reglas del cambio electoral dentro del sistema político", ibid., p. 88.

40 "Tres fenómenos ayudan a comprender. los límites de la representación puramente electoral y de la democracia considerada en un nivel puramente político. El primero tiene que ver con la relación entre cambios legales de gobierno y cambios violentos; el segundo con los procesos electorales y la libertad relativa de los partidos políticos, y el tercero con la crisis de los sistemas políticos, cuando se plantea el cambio del sistema social o de sus estructuras". ibid.

41 Ibid., p. 98.
Otro problema que plantea González Casanova es que la democracia se asienta en una determinada hegemonía, y que para reconstruir la democra. cia es necesario configurar una nueva hegemonía que no va a ser de la clase obrera, sino de un amplio conjunto del pueblo. Y esa lucha, empero, involucra la búsqueda de lo civil y lo constitucional: "una alternativa revolucionaria que es democrática y popular, más bien que obrera y socialista". 42

A partir del concepto "bloque dominante", el autor ubica adecuadamente el problema de la democracia como una rclación social de poder, en la cual las instituciones y las políticas estable. cen un vínculo con determinadas clases y grupos sociales, y es entonces donde adoptan su real significado.

El bloque dominante constituye la estructura social de dominación y uso de la fuerza, la riqueza y el excedente. Corresponde a la articulación de las distintas burguesías (nacionales, transnacionales) entre sí y con las fuerzas represivas, de conciliación, arbitraje y negociación, así como la representación cooptada: obrera, campesina, de clases medias, de pobladores urbanos, de gremios profesionales o de electores y "ciudadanos". El bloque dominante es la estructura hegemónica del Estado en el conjunto de sus relaciones sociales. ${ }^{43}$

Tiene razón el autor cuando señala que es a la luz del bloque dominante como se puede evaluar la falta de democracia en América Latina:

12 Ibial, p. 101

$\$ 3$ lbid., p. 104 . 
El bloque dominante es un "gobierno encima del gobierno" que afronta los desafíos con el gobierno o que cambia de gobierno. Es una estructura que está por encima de las instituciones del Estado y de los sistemas o regímenes políticos, y que los combina con dos lógicas, la de acumulación y la del poder. ${ }^{44}$

El texto de González Casanova desnuda los hechos ocultos en la restauración y profundización de la democracia en la década de los ochenta. Quizá por acentuar que el verdadero poder político está en una elite transnacionalizada y dominada por los gobiernos y organismos financieros de

${ }^{44}$ Ibid., p. 105. los países de capitalismo avanzado, conceda poco a la movilización popular que arrancó los Estados constitucionales de derecho hoy día predominantes en la región. Este autor tampoco acentúa lo suficiente que precisamente por ser una relación social específica de poder, la democracia permite que los pueblos se expresen y que las clases y grupos sociales luchen por influir en el Estado de manera abierta, amplia y legal, en beneficio de su propio desarrollo político y de la constitución de un proyecto alternativo. No obstante, resulta alentador encontrar una apreciación rigurosa y crítica de la democracia política latinoamericana en los noventa. Eso demuestra que la sociología política radical todavía tiene capacidad para el conocimiento de América Latina.

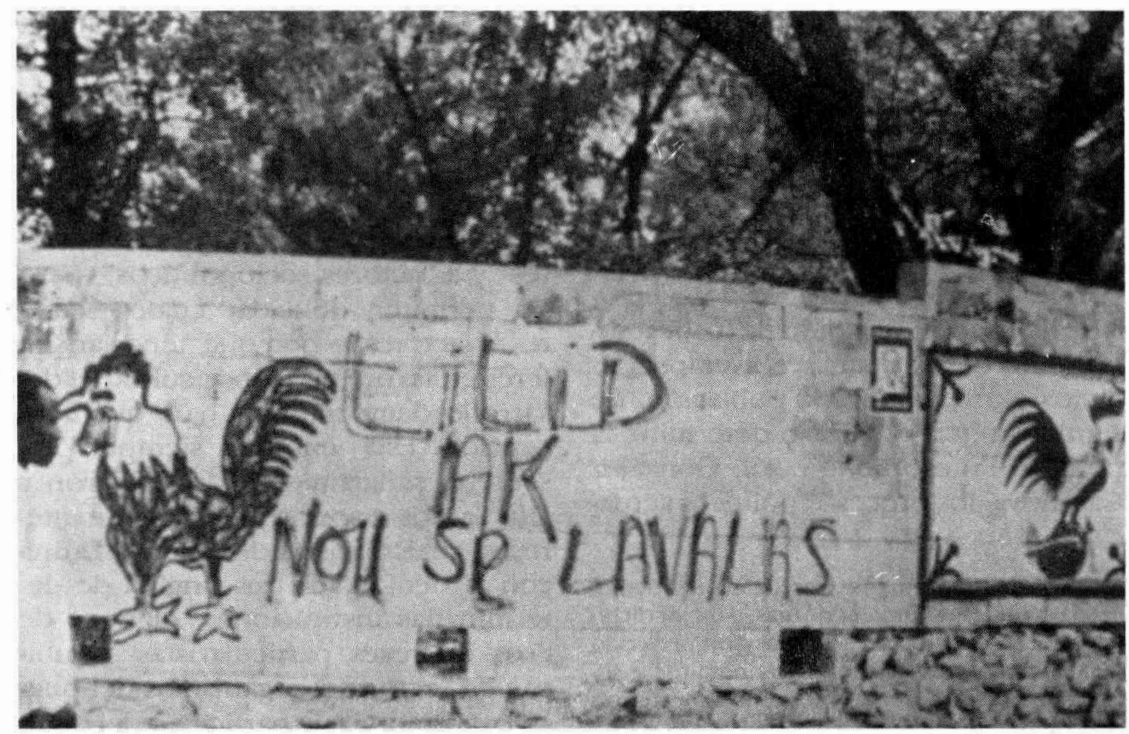


LA TEORÍA EN LA DEMOCRACIA LATINOAMERICANA

Apreciaciones tan divergentes como las que nos presentan las lecturas, nos demuestran que la cuestión de la democracia política en América Latina es un problema teórico y no sólo una referencia empírica a encontrar. Lo primero que resalta es que en realidad hay distintas concepciones de la democracia política: una concepción de elite (pro capitalista) de la democracia política y una concepción popular (crítica) de la misma. En la primera, la soberanía de la nación y la participación política republicana en la toma de decisiones está vinculada a la gobernabilidad y a la legitimidad en términos de los criterios de la modernidad. Pero no se cuestiona ni el poder del capital ${ }^{45}$ (nacional y transnacional), ni el poder autónomo de la burocracia, cada vez más fortalecida y autonomizada de la sociedad. Tampoco se alude a lo que debería se esencial: la determinación creciente por la colectividad total de las grandes decisiones políticas y de los proyectos de desarrollo nacional. Las elecciones periódicas, el respeto a los derechos y a las libertades, un grado de justicia social y una eficacia para resolver los con. flictos e involucrar a la población, no significan que el pueblo determine la política. En eso tiene razón González Casanova: los procesos políticos actua-

15 "Lamentablemente, las flamantes democracias políticas latinoamericanas, o mejor dicho los gobiernos resultantes de ellas, han preferido dejar libradas las cuestiones económicas y sociales más urgentes a las fuerzas del mercado", véase Emmerich, "América", 1991, p. 227. les están en manos de entidades estatoides transnacionales y no de los pueblos. Una profundización de la democracia política implica grados crecientes de soberanía popular, es decir, control popular sobre las grandes fuerzas de nuestra época: el capital y la burocracia. Hoy eso está perdido en la gran mayoría de nuestros países; no obstante, su recuperación empieza por cuestionar la concepción elitista dominante de la democracia política y se desarrolla en la lucha por instituciones y prácticas abiertas y libres que desarrollen la capacidad y la posibilidad de acción política popular.

Una cuestión que nos sorprendió en las lecturas es que el problema de la democracia se ubica en general en términos de las grandes tendencias del desarrollo económico, social y político de las formaciones latinoamericanas, pero no en función de la posibilidad y la voluntad política de fuerzas sociales; pareciera un asunto de programas y proyectos y no de conflicto de clases sociales y grupos de poder.

Los conceptos utilizados por las dos primeras vertientes aluden a "sectores" y a "actores sociopolíticos", pero no permiten dilucidar cuáles sectores o actores y por qué tendrían interés en favorecer u obstaculizar el desarrollo democrático y bajo qué concepción. Está, empero, siempre presente el señalamiento de Calderón y Dos Santos respecto al vínculo de intereses particularistas de América Latina con la democracia restringida de cle. terminadas instituciones. Algunos de esos intereses particularistas se ubican en sectores y organismos del pueblo trabajador que participan del exce- 
dente estatal y que han sido cooptados por el poder real. Precisamente por ello, y por acudir a criterios terrenales sobre las fuerzas interesadas en la profundización de la democracia, siempre es mejor ubicar las tendencias, los intereses y los conflictos en torno de las clases y grupos sociales actuantes en la realidad latinoamericana de hoy.

González Casanova, por el contrario, atina a ubicar en el pueblo trabajador un interés específico por la democracia en términos de desarrollo político y mejoramiento social, y una manipulación formal de la misma por parte de las elites transnacionales y nacionales del poder, con el fin de ocultar la vulnerabilidad de un proyecto de elite.

Lo que debía estar claro es que las instituciones y las políticas tienen siempre una referencia social que les da sentido y funcionabilidad. Además de la autonomía burocrática, es también el vínculo con los empresarios transnacionales, los militares y las elites de poder lo que hoy día hace no democráticas a instituciones que según el Estado de derecho debían expresar los intereses del pueblo. No estamos diciendo que las instituciones republicanas de los Estados latinoamericanos estén del todo en manos de las elites, sino que en el contexto de la dominación política de dichas elites las instituciones son funcionales para esa dominación. Además las instituciones cristalizan normalmente el momento constitutivo que les da vida en términos políticos y en términos de hegemonía de clase. ${ }^{46}$

46 Zavaleta Mercado, Estado, 1984.
Precisamente por lo anterior es que sigue vigente, en términos de lucha por la hegemonía, una concepción popular de la democracia política que ponga el acento en la participación de toda la sociedad en la toma de decisiones fundamentales y permita la organización y el desarrollo político del hasta ahora fragmentado pueblo trabajador. La transnacionalización del Estado latinoamericano, señalada por González Casanova, y la vacuidad de las formas actuales de democracia política para expresar una soberanía popular, hacen más urgente que nunca la lucha por una democracia política distinta.

\section{Bibliografía}

-Alfonsín, Raúl y otros, Agenda para la consolidación de la democracia en Amé. rica Latina, Instituto Interamericano de Derechos Humanos, Fundación Friedrich Naumann, San José, Costa Rica, 1990.

-América Latina a finales del siglo $x x$, Centro de Estudios LatinoamericanosFacultad de Ciencias Políticas y sociales, UNaM, México, septiembre de 1990.

-Calderón, Fernando y Mario R. dos Santos, "Hacia un nuevo orden estatal en América Latina; veinte tesis sociopolíticas y un corolario de cierre", Nueva Sociedad, núm. 110, Caracas, Venezuela, noviembrediciembre de 1990.

-CEPAL, Balance y perspectivas de la economía de América Latinna y El Caribe, Ed. Naciones Unidas, diciembre de 1990.

-Emmerich, Gustavo Ernesto, "América Latina, fin de siglo: consolidación democrática, involución económica y rezago social", Iztapalapa, año II, núm. 23, juliodiciembre de 1991.

-González Casanova, Pablo, "La crisis del Estado y la lucha por la democra- 
cia en América Latina", Nueva Sociedad, núm. 104, Caracas, Venezucla, noviembediciembre de 1989.

, y otros, América Latina boy, ONU/Siglo XXI Editores, México, 1990.

(coord.), El Esiado en Amé-

rica Latina. Teoría y prácrica, ovU-Siglo XXI Editores, México, 1990.

" "La crisis del Fistado y la democracia en el sur", cn Memoria, núm. 440, Revista del CEMOS, marzo de 1992.

-Landau, George, y otros, América la. tina en la encrucijada; el desafio de los países de la Tilateral, Tecnos-Centro de Estudios de Política Exterior; Madtid, 1990.

-Portantiero, Juan Carlos, "La múltiple transformación-del Estado latinoamericano", Nueva Sociedad, núm. 104, Caracas, Venezuela, noviembre-diciembre de 1989.

-Raimondi Ezequiel y Fabián Echegamy, "Repensando ho democracia desde el ajustc; una perspectiva crítica", Nucua Sociedad, núm. 113, Caracas, Venezucla, mayo-junio de 1991.

-Rodrigucz Elizondo, José, "América Latina: hacia la democracia consolidada", Nueva Sociedad, núm. 113, Caracas, Venezucla, mayo-junio de 1991.

Seminario dicilogo interregional sobre desamollo, democracia y pensamiento critico, Centro de Estudios del Desartollo (CENDES), Facultad de Ciencias Económicas y Sociales de la Liniversidad Centual de Venezuela y el Instituto Starnberg de Alemania, Venezuch, octubie de 1990.

-Vuscovic, Pedio, "Economía y crisis", en Pablo González Casanova, América Latina boy, oNU/Siglo XXI Editores, México, 1990.

-Zavaleta Mercado, René, "El Estado en América Latina", en Ensajos, Ed. DEP, Facultad de Economía-unam, México, vol. I, núm. 1, 1984. 